Faculty of Education

Te Kura Toi Tangata

Waikato Journal of Education

Te Hautaka Mātauranga o Waikato

Volume 16, Issue 2: 2011 


\section{WAIKATO JOURNAL OF EDUCATION TE HAUTAKA MĀTAURANGA O WAIKATO}

\section{Editors:}

Jane Strachan

Noeline Wright

\author{
Editorial Board: \\ Beverley Bell \\ Bronwen Cowie \\ Deborah Fraser \\ Margie Hohepa \\ Sally Peters \\ Noeline Wright
}

\author{
Margaret Carr \\ Rosemary DeLuca \\ Richard Hill \\ Judy Moreland \\ Clive Pope
}

Waikato Journal of Education is a refereed journal, published annually, based in the Faculty of Education, The University of Waikato, Hamilton, New Zealand. It publishes articles in the broad field of education. For further information visit the WJE website http://edlinked.soe.waikato.ac.nz/research/journal/index.php?id=8

Correspondence and articles for review should be addressed to: Research Manager, Wilf Malcolm Institute of Educational Research, Faculty of Education, The University of Waikato, Private Bag 3105, Hamilton, 3240, New Zealand. Email: wmier@waikato.ac.nz

Business correspondence: Orders, subscription payments and other enquiries should be sent to the Administrator, Waikato Journal of Education, Wilf Malcolm Institute of Educational Research, Faculty of Education, The University of Waikato, Private Bag 3105, Hamilton, 3240, New Zealand, Email: wmier@waikato.ac.nz

Subscriptions: Within NZ \$40; Overseas NZ \$50

Copyright: (C) Faculty of Education, The University of Waikato

Publisher: $\quad$ Faculty of Education, The University of Waikato

Cover design: Donn Ratana

Printed by: Waikato Print

\section{Call for papers}

The Waikato Journal of Education provides an avenue of publication for quality articles on education. This peer-reviewed journal welcomes a range of topics including interdisciplinary, philosophical and applied research approaches.

Submissions are now invited for consideration for publication in the November 2012 issue. Please submit an electronic copy and a separate page with author/s contact details by 30 April 2012 to WMIER Research Manager, Carolyn Jones (cjjones@waikato.ac.nz), Faculty of Education, University of Waikato, Private Bag 3105, Hamilton 3240, New Zealand. 


\section{Waikato Journal of Education}

\section{Te Hautaka Mātauranga o Waikato}

Volume 16, Issue 2: 2011

\section{Special Edition: A teacher education partnership between the Solomon Islands and New Zealand}

Editorial

The Solomon Islands School of Education Partnership: Aspirations, context and design in educational change

Clive McGee and Patricia Rodie

Partnership experiences in developing the Preparation for Tertiary Learning course in the Teachers in Training programme

Roselyn Maneipuri, Immaculate Runialo and Noeline Wright

Making sense of health education in the Solomon Islands

Kirsten Petrie and Mark Tehe

The Solomon Islands mathematics: Pedagogy in transition?

Nigel Calder, John Beuka and Calvin Ngatulu

Taking ownership: The story of a successful partnership for change in a Pacific Island science teacher education setting

Richard Edwards, Solomon Pita and James Porakari

Funds of knowledge: Developing a Diploma in Teaching in Early Childhood Education in the Solomon Islands

Janette Kelly, Joanna Daiwo and Viola Malasa

Weaving a "Hybrid Mat": Samoa meets the Solomons

Barbara Whyte

Sustaining organisational change: Teacher education in the Solomon Islands Jane Strachan, Susanne Maezama and Janine Simi

Exploring factors that influence school planning in community high schools in the Solomon Islands: Principals' perspectives

Samuel Aruhu and David Giles

Experiences of being a leader in Choiseul Province: Opening principals' and deputy principals' contexts of leadership

John Sisiolo and David Giles

Book review 


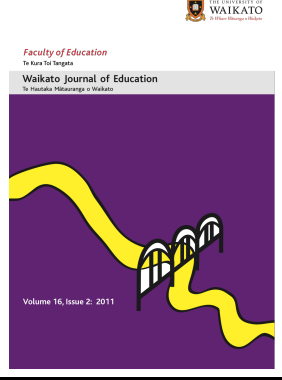

\title{
Sustaining organisational change: Teacher education in the Solomon Islands
}

\author{
Jane Strachan \\ Faculty of Education \\ University of Waikato

\section{Susanne Maezama and Janine Simi} \\ School of Education \\ Solomon Islands College of Higher Education
}

\begin{abstract}
"Sustainability is the capacity of education reform initiatives to continue" (Webster, Silova, Moyer, \& McAllister, 2011, para. 12). In this article we reflect upon the process of organisational strengthening that was a key component of the Partnership between the Faculty of Education at the University of Waikato and the School of Education, Solomon Islands College of Higher Education. We argue that within the New Zealand Aid Programme funded partnership, the building of mutually respectful relationships, building leadership capacity and the respect for and inclusion of indigenous cultural considerations were key to the organisational change process and its sustainability.
\end{abstract}

\section{Keywords}

Partnership, organisational change, teacher education, Solomon Islands.

\section{Introduction}

The Solomon Islands experienced a period of serious ethnic conflict between 19982003. ${ }^{\text {ii }}$ This led to the displacement of some 20,000 people and the inability of the government to deliver services such as teacher education. With the arrival of the Regional Assistance Mission to the Solomon Islands (RAMSI), some stability gradually returned and aid poured in from donors to assist the rebuilding process. Education (Kaua \& Sore, 2005) ${ }^{\mathrm{iii}}$, including teacher education (NZAID, 2006), was a major recipient of donor funds.

Partnerships and relationships have been central to the New Zealand Aid Programme and "these related terms imply that aid agencies wish to develop linkages

Faculty of Education, University of Waikato, Hamilton, New Zealand

ISSN: $1173-6135$

(pp. 95-106) 
with recipient agencies and communities that endure over time and which involve some degree of two-way interaction" (Overton \& Storey, 2004, p. 41). New Zealand funded a three-year ${ }^{\text {iv }}$ support relationship Partnership (from now on known as the Partnership). The partnership that was designed twinned the School of Education (SOE), Solomon Islands College of Education (SICHE) ${ }^{\mathrm{v}}$ with a New Zealand teacher education provider, the Faculty of Education, University of Waikato (UOW). The principles of "partnership" and "relationships" were the twin pillars on which the project stood.

At the start of the Partnership, the SOE programmes were out of date, facilities and resources very poor, staff morale low and there was a lack of strategic planning (NZAID, 2006). The SOE could thus be described as a failing organisation (Murphy, 2010). This is commonplace in fragile states, where "... these concepts [fragile states and fragility] incorporate ideas that underline a government's weak capacity to provide social services such as education" (Mosselson, Wheaton, \& St. John Frisoli, 2009). So, the Partnership was given an organisational strengthening mandate that involved enhancing management practices, improving the morale, skills and knowledge of SOE staff, and reviewing and redesigning the teacher education programmes to reflect current teacher education practices that would be appropriate to the Solomon Islands context (NZAID, 2006).

Part of the organisational strengthening process involved the development of a teacher education curriculum for early childhood, primary and secondary teachers and this is the focus of other articles in this special edition. Alcorn (2010) framed the Partnership as action research and identified four action cycle phases: programme development and new teaching strategies, organisational changes, leadership and change, and research promotion and dissemination.

This article will focus on those aspects of the Partnership that were designed to enhance the sustainability of, and support the changes to, the academic programmes and improve management processes.

Webster et al. (2011) suggest that a holistic approach to sustainability is desirable including "... examination of specific processes used to keep the project sustained over a longer period of time" (para. 16). So, while organisational change is the focus (the second phase of Alcorn's action cycle) of this article, the importance of relationship building, increasing the leadership capacity of all staff and the valuing and inclusion of indigenous considerations will be given particular attention as they were considered key to the organisational strengthening process.

\section{Organisational change}

Murphy (2010) suggests five connected approaches to turning around an organisation:

a. chronicle stories of the recovery process,

b. distill elements, characteristics, ingredients, and principles of successful transformation,

c. discuss turnaround actions, approaches, and strategies,

d. delineate phases, steps, or stages of turnarounds, and

e. display explanatory models of how organizations move from sickness to health. (p. 158) 
While Murphy (2010) provides a useful framework for turning around an organisation, consideration of the context is also vital as research tells us that culture significantly influences organisational practices (Strachan, Akao, Kilavanwa, \& Warsal, 2010) and therefore influences the organisational change process. Central to the process is how positive and respectful working relationships are established; this was indeed the case for this Partnership.

\section{Relationship building}

In mid 2006 the UOW staff arrived in the Solomon Islands to meet for the first time the staff they were to work with over the next four and a half years. They were therefore unknown to the Solomon Islands staff and were regarded with some suspicion. One SOE staff member commented: "We felt a bit intimidated and inadequate because you had doctorates and some of you were professors" (Susanne). Some SOE staff were unclear what the Partnership was for as they had not been consulted during the planning phase. Some thought the Partnership would provide tangible resources such as computers, laptops and library books. One of the first tasks was therefore to clarify the parameters of the Partnership and how we envisaged working together.

"Resource transfers from rich to poor countries" through aid (Kanbur, 2001, p. 6) take many forms. And while there were some tangible resources gifted to the SOE, the transfer of non-tangible resources during the partnership was in both directions: from the UOW to the SOE and from the SOE to the UOW. The resources were skills, expertise, and knowledge, including Solomon Islands cultural knowledge. However, before this transfer could take place, mutually respectful relationships needed to be built.

Aid fatigue can occur for donors (Kanbur, 2001) but also for recipients, as was observed at the SOE. Staff thought the UOW would come in and "tell us what to do and how to do it" (SOE staff member) as this had happened before in previous aid projects. This had limited SOE staff involvement and ownership of the changes and consequently the sustainability of those changes. Jansen (2009) is scathing of what he calls "patronising thinking" in the flow of information from developed to developing nations on organizational change: “... the assumption is that one side knows and the other side does not, and those who know have to 'aid' those that do not. This is obviously offensive on so many levels" (p. 242). So, a different approach was needed. The different approach affected the selection of UOW staff to work with SOE staff.

While obviously the UOW staff professional expertise was very important, so was how they chose to work with others. "I wanted people who not only worked with their heads but with their hearts too" (Jane). A collegial, inclusive approach that valued what the other person brought to the Partnership was essential, and some experience of working with other cultures was desirable. If they had worked in the Pacific Islands, even better. Not all UOW staff met all these criteria, but all were collegial and inclusive. This was a critical factor in building trusting relationships and has been detailed in other articles in this special edition. However, as with a teacher education reform programme in Latvia, this Partnership

... was based on the idea that offering new information and ideas was not sufficient by itself. Instead it would be more effective to support participants in understanding a problem, generating their own insights 
with regard to different ways of addressing the problem, and, more importantly, facilitating implementation strategies which would be appropriate to their particular educational purposes. (Webster et al., 2011, para. 9)

In the Solomon Islands context, the strategies had to be inclusive and considerate of the local cultures. All UOW staff that worked within the Partnership were appraised of the approach, understood it and were committed to it. Over about six months, the SOE staff began to trust that their UOW colleagues valued their expertise and knowledge and weren't there to "do it to them". In post-conflict societies, trust is often a casualty and this was the case in the Solomon Islands (Dulcie Paina, personal conversation, 2007), so doing what was promised was critical to building trusting relationships and "the importance of trust cannot be underestimated in the success of the project [reforming teacher education in Latvia]" (Webster et al., 2011, para. 30).

Expatriate consultants working in international aid are often highly paid (Jansen, 2009). In comparison, their local counterparts often struggle to house, feed and clothe their families. Understandably, resentment can occur, which is detrimental to building close working relationships. In the past, consultants were sometimes perceived as being there just for the money, “ ... or they expected too much from the SOE staff with no immediate feedback/feedforward and genuine support, [there were] no activities that build capacity" (SOE staff member).

The UOW staff, on the other hand, were not paid as consultants to undertake their work at the SOE. Rather, this was considered to be part of their work for the UOW, although their expenses were covered when they visited the Solomon Islands. However, they were deliberately positioned as Partnership staff not consultants. The SOE staff were informed of this and this helped to narrow the divide between well-paid international consultants and poorly paid local counterparts. "You came as staff of Waikato not as consultants, that helped [build relationships]" (Susanne).

During one of our first meetings, SOE staff were asked to identify how they would like to work with the UOW staff, what sort of place the SOE was at that time and what they would like it to be. Finally, they were asked, what sort of teacher education graduate did they want their programmes to produce? This was a time for the UOW staff to listen. The SOE staff said they wanted to teach high quality teacher education programmes that were relevant to the Solomon Islands context. Specifically, they wanted the $\mathrm{SOE}$ as a teacher education organisation to

1. be academic and research based;

2. be attractive;

3. have motivated staff;

4. have efficient systems;

5. have good facilities and be well equipped;

6. have strong links with schools;

7. have a holistic approach to teaching and learning;

8. be autonomous;

9. have realistic workloads and less assessment;

10. be cost-effective; 
11. have demonstration schools; and

12. have a good flow of information within SOE.

While not all of these were within the mandate of the Partnership, for example, selecting a demonstration school, the information gathered during this session informed planning for the Partnership. It also gave UOW staff an insight into what it was like to work at the SOE. The next session focused on the change process and what we were all likely to experience as we journeyed through this Partnership together. For example, change can be unsettling and/or chaotic, does not go in a straight line, has phases, involves give and take and problem solving. And some factors are beyond everyone's control. Towards the end of the Partnership the change process was revisited and discussed with reference to what had taken place over the four and a half years of the Partnership. The SOE staff reflected and were able to identify with the different phases and characteristics of the change process. A SOE staff member commented:

... having the workshop on the change process at the beginning of the partnership helped us to understand what to expect, also SOE. SOE/Waikato, NZAID participating in framing the TOR of the partnership was crucial in building trust. (Susanne)

This was part of the relationship-building process and transparency was an important part of building trust. Trust was critical to the continuity of the Partnership (Webster et al., 2011).

Although the Partnership was located at the SOE in the Solomon Islands, the SOE had key relationships with both the SICHE and the Ministry of Education and Human Resource Development (MEHRD). The Partnership was also tasked with improving the relationship the SOE had with the SICHE and the MEHRD. These relationships were fragile as the SICHE and the MEHRD were also in difficulty and experiencing a lack of capacity in terms of human resources, funding and management efficiency. While both organisations were receiving some donor assistance, some SICHE staff felt that the SOE was being "favoured" because of the significant support it was receiving through the Partnership. When the Partnership was originally designed, those involved were from the SOE, the New Zealand Aid Programme and the MEHRD. The SICHE had not been consulted so staff did not know what was happening or why it was happening. This added a complexity to the work of the Partnership, as having strong working relationships with the SICHE and the MEHRD was essential to the SOE organisational change process and its sustainability. For example, any changes to the academic regulations for the new qualifications needed the approval of the SICHE Council. At times there was filibustering by SICHE staff and approval was delayed.

\section{Leadership}

For educational reform to be effective, leadership competence is critical to sustainability (Mancini \& Marek, 2004). Within the context of a developing and fragile country such as the Solomon Islands, there are significant differences in understanding the role of leaders/leadership compared with how those are understood in Western contexts (Oplatka, 2004).

Oplatka (2004) suggests that in developing countries principals (educational leaders) have "constrained autonomy" (p. 431) and are more likely to act as managers and administrators and "employ an autocratic rather than participative leadership style" (p. 
431). The leadership within the SOE had reflected a focus on administration and management rather than on the leadership of learning. Leading learning and supporting quality teaching within a context of very poor facilities and resources, as was the case with the SOE, was a Herculean task and not one that educational leaders in the Solomon Islands necessarily saw as their role (Ruqebatu, 2010). Supporting and enhancing leadership at the SOE was identified early in the Partnership as the key to continuity, particularly in embedding organisational processes and systems to support learnercentred teaching.

As with other developing countries, teaching and learning in the Solomon Islands had been/is mainly teacher directed. Learner-centred education "has been largely sponsored by international aid agencies" (Mtika \& Gates, 2010, p. 397). This same orientation was a cornerstone of this partnership, and was "sponsored" by both the New Zealand Aid Programme and the UOW. Jansen (2009), however, is critical of the move to import Western ideals of learner-centred education into developing countries.

Learner centred education assumes political cultures and social traditions that support and embrace notions of individuality of the child, the freedom of children to question adults, an open society that values participation and dissent, and authority relationships based on what people achieve rather than on the accident of age, gender, ethnicity, religion or caste. Many developing countries have deeply rooted authoritarian traditions and democratic practices are unevenly rooted in social and institutional practices. (p. 240)

While acknowledging Jansen's (2009) point, the SOE staff, their students and the students they taught on their teaching experiences were thirsty for new ways of teaching and learning. They relished experiencing and trialling the learner-centred approaches they learned through their involvement in the partnership. Feedback from the SOE staff on learner-centred teaching was very positive, although lack of resources was and continues to be an issue (Alcorn, 2010). So, while learner-centred approaches may not have "taken root in classrooms" (Mtika \& Gates, 2010, p. 397) just yet, an enthusiastic start was made.

Supporting leadership occurred throughout all levels of the SOE. A very experienced leader of teacher education at the UOW worked with the senior management team as a leadership mentor throughout the four and a half years of the Partnership. During that time, there were three different women in the Head of School position and each appointed two assistant heads, one with the responsibility for administrative matters and the other for academic matters. In addition, a senior SOE staff member was appointed to manage partnership matters. Both the leadership mentor and the director of the Partnership had frequent contact with the Head of School and the Partnership coordinator while in the Solomon Islands and when back in New Zealand. This regular contact was important in building relationships and also in problemsolving. In the first three years of the Partnership, the SOE senior teams did not work well together, and this presented the Head of School with some difficult performance issues. Differences were deeply embedded in the culture, partly because "traditional leadership also incorporates sexist views [of leadership]" (Ruqebatu, 2010, p. 107) and efforts to team-build were largely unsuccessful.

At that time, the lack of support from senior management at the SICHE meant that the Head of School had to handle performance issues on her own. The leadership 
mentoring aspect of the Partnership proved to be a lifeline and a welcome opportunity to confidentially discuss issues and possible strategies. In the last year of the Partnership a new Head of School was appointed who had previously been the Partnership coordinator, and a "project champion" (Webster et al., 2011, para. 27). She then appointed the previous Head of School ${ }^{\mathrm{vi}}$ (HOS) and a head of department as her two assistants. They were selected because of their knowledge of the Partnership and its goals including the new qualifications and learner-centred approaches, and their proven administration abilities. This was a significant departure from how previous decisions of this nature had been made: "I wanted people [as the Assistant Heads of School] I could rely on and who were hard workers" (Janine). These appointments were thus based on merit rather than seniority, which had often been the main criterion for advancement in the past.

The Partnership leadership mentoring continued and the SOE senior team worked very well together. With the support of her two assistants, the HOS was able to push forward with the organisational changes designed to support the academic programmes, for example, policy development and academic regulations. The senior management team met regularly and planned for the future. This process was more active than reactive, and linked to a more distributive rather than autocratic leadership.

The notion that leadership was a shared responsibility and not just vested in the person who held a formal leadership position was not always well received. Delegating was interpreted by some as the HOS shirking her responsibility. Others welcomed the chance to be more involved in decision-making. During the last year of the Partnership, a number of key tasks critical to the ongoing sustainability of the organisational changes were identified. For example, course and programme review, policy development, development of a Bachelor of Teaching degree, upgrading qualifications, adult education review and revision, and ICT all needed ongoing attention. Teams of SOE staff were allocated to each of the tasks. Leaders were appointed for each, and teams wrote their terms of reference. A member of the senior management team also attended the planning meetings for each team, demonstrating the importance of the task.

The leadership potential of individual SOE staff was identified and those people were mentored into new roles. Some had just returned from overseas study, successfully completing their master's degrees, some of which were in educational leadership. Their new skills and knowledge were quickly put to use in taking on responsible roles such as a head of department or a programme co-ordinator, often replacing people who had not been performing satisfactorily. Returning graduates are often keen and motivated to put to use their new knowledge but can be frustrated when opportunities are not provided (Strachan, Samuel, \& Takaro, 2007), and so having their new skills and knowledge recognised early was important for their professional self-esteem.

The staff as a whole were also involved in leadership development. During the early stages of the partnership, the SOE staff indicated that they wished to include a course on leadership and management in the pre-service teacher education programmes. Teachers in these communities are often asked to take on leadership roles and it is not unusual that a recently graduated teacher is appointed as the principal of a school in a remote community. In addition, there was widespread concern about the poor professionalism of some teachers; absenteeism was very common. Poor working conditions, including housing ("Teachers non-attendance due to housing", 2008) and very low salaries contribute to both the high rate of absenteeism and the difficulty in 
recruiting teachers (Ruqebatu, 2010). A leadership and management course was, once developed, well received, particularly by those who had some previous teaching experience before their teacher education. A course on its own was unlikely to solve teacher professionalism and recruitment issues, but it was a start.

The leadership course led to two further leadership development opportunities. The first opportunity was professional development in leadership and management, mainly designed for the SOE senior and middle managers, but open to other SOE staff who wished to attend. This professional development opportunity was in response to a need for leadership development identified by both the SOE and UOW partners. As previous attendance at professional development workshops had not been large, this one was organised differently. The content was negotiated with staff. Three modules were identified: leadership, organisational development and working with others. The programme was formally organised through the UOW. Participants who attended all 12 sessions received a certificate of participation from the UOW. The kaupapa ${ }^{\text {vii }}$ of the programme was participatory and learner-centred. All activities were designed so they could be used by the SOE staff when teaching the leadership and management course. Discussion took place as to how the activities might be adapted using local material and knowledge. There was also an emphasis on fun and humour.

The second opportunity came via a request from the MEHRD for the SOE to provide leadership training for school principals as there was a "lack of appropriate preprincipalship training or professional development: no principals are trained for their task" (Ruqebatu, 2010, p. 107). The SOE were keen to take on this role and knew that it would require careful planning. An SOE staff team with expertise/qualifications in leadership and management was established to develop and implement this programme for principals. The team decided to design a qualification at certificate level. The qualification would use the new qualification structure (120 credits), building on the undergraduate course in leadership and development, and adopt much of the material in the UOW certificate programme in leadership and management. This was an example of scaffolding the learning the SOE staff experienced during the Partnership and demonstrated their willingness to take leadership. Their excitement at being involved in the development of the qualification was also indicative of their improved morale and professional confidence.

Building leadership capacity is crucial to the sustainability of organisational change (Murphy, 2010), within the Solomon Islands context, but this goes hand in hand with respect for, and inclusion of, indigenous cultural considerations.

\section{Indigenous cultural considerations}

Research literature shows that culture and context matter (Crossley, 2001) when working within small Pacific states (Coxon \& Munce, 2008). However, Coxon and Munce (2008) argue that "little attention [has been paid] to particular regional or national needs" (p. 148) when decisions are being made about what and how aid should be delivered to education in developing countries. While this point had been a common feature of aid to date, this partnership, from the outset, was based on "a strong two-way sharing of ideas based on an appreciation of cultural differences and with activities utilizing strong cultural sensitivities" (NZAID, 2006, p. 4). The SOE staff were also insistent that in pursuit of high quality teacher education, Solomon Islands culture had to be central to the process. After all, the SOE staff were preparing teachers to teach 
within the Solomon Islands context. For the UOW staff, this was both familiar and different, presenting a number of challenges. It was familiar as their own teacher education practices involved a respect for, and inclusion of, Māori concepts such as ako (the reciprocity of teaching and learning) and a commitment to the three principles of the Treaty of Waitangi: partnership, participation and protection. As Alcorn (2010) commented about the UOW Partnership staff, "They were [also] mindful of the fact that they were not the first New Zealand team to see themselves as learners in a new cultural situation" (p. 456).

It was also different and challenging work. Time is a fluid concept in the Solomon Islands. In New Zealand, however, this is not the case; meetings are supposed to start on time, as scheduled. There were many occasions when members of the UOW team waited and waited for meetings to start; often resulting in a feeling that time had been wasted. Prior to the start of the Partnership, the UOW staff were briefed that they would experience this, and it was important not to show displeasure or frustration. Many used the waiting time to chat with others, or do reading or planning. Another challenge was the "cultural practice of 'wantok', a system by which the traditional Solomon Islands leader is culturally obliged to serve his or her clan or tribe before others" (Ruqebatu, 2010, p. 107).

It was hard for us to understand the wantok system especially in a professional setting. From a New Zealand Pakeha cultural perspective this ran counter to good leadership practice. It seemed that this meant often the wrong person was appointed to a position just because they were related to someone, or senior to someone. It leaves the door wide open to allegations of corruption. (Jane)

Difficulties that can be caused by the wantok system were well illustrated in the selection of the first cohort of pre-service teachers for the 2009 intake. The upgraded teacher education qualifications, developed through the Partnership, required new selection criteria and this included increasing the standard of entry education requirement. However, there were many instances of students being selected who had not met the new criteria. This was blamed on the wantok system and resulted in those students struggling academically, and in some cases failing.

Many of the SOE and the SICHE staff who had studied overseas had experienced approaches to organisational management that did not involve the wantok system. This provided them with tensions and challenges on their return as they tried to implement these new approaches (for example, appointments to jobs or selecting students for teacher education on merit) within a wantok system. As one such staff member said, "I get a lot of pressure from wantok to favour them. I explain that I am here [in a leadership position] for everyone not just them. It's hard, sometimes they think I am mean and have lost my culture" (SICHE staff member).

While it was unlikely that the Partnership would change the wantok system, or should, there was an increasing willingness on behalf of the SOE staff to both engage in practices that were fairer and more equitable within the professional setting of teacher education, and to challenge occasions when they perceived other staff were abusing the wantok system. This was illustrated when a SOE staff member put pressure on another staff member to change the grade of a relative who had failed a course. The staff member refused to change the grade and was supported in this decision by senior staff. However, such stands can be difficult, and, when wantok pressure is applied from a 
senior male to a female staff member, this pressure is even harder to resist since gender relationships are often implicated.

The importance of Christianity in the lives of Solomon Islands people was another important cultural consideration within the partnership. Although Christianity is not indigenous to the Solomon Islands, the centrality of it in both the professional and personal lives of Solomon Islands people cannot be underestimated. It has a profound influence on education and is a stabilising aspect of Solomon Islands culture. Most Solomon Islanders are regular churchgoers. Pastors are very influential and highly respected and the education system is based on Christian values (Ruqebatu, 2010). This contrasts with New Zealand's more secular education system and, although a number of schools have a special Christian character (mainly church, private or integrated schools), religion has a muted influence in New Zealand education.

Christianity thus had to be central to the Partnership activities as this not only respected the local cultural context, but also contributed to the likelihood of sustainability of the changes instigated in the SOE. The Christian ethos showed itself in a range of ways, from the teacher education course content, meeting conduct (with an opening and closing payer), and the development of a teacher education course specifically for teachers of religious studies, based wholly on Christianity. This provided another challenge for the UOW staff, most of whom were not practising Christians. This was not because they were unwilling to respect and support the central role of Christianity in teacher education in the Solomon Islands, but because they had little professional experience of doing so. This was an example of where local expertise in content knowledge was used, alongside the needed shift in pedagogical practices: from teacher-centred to learner-centred approaches in teaching Christian education. Relying on and developing local expertise was critical to the process of organisational change. This reliance on local expertise and cultural knowledge was important for the sustainability of the wider professional changes.

\section{So what?}

We (the authors) are often asked whether the Partnership has made a difference and if it is sustainable in the long term. This is difficult to determine after four and a half years, since changes of this nature take some time to take hold. We do know it has already made a difference in a number of ways. These include a new qualification structure, new teacher education curriculum, research, learner-centred teaching, and improved staff morale and capacity. However, those changes need both strong organisational processes to support them and strong leadership to ensure that staff are vigilant in following those processes. This vigilance, for example, has to be shown in implementing and adhering to the new assessment policy. Without continual review and monitoring, it is too easy to fall back on the old ways of doing things because they are familiar and comfortable. However, the long-term sustainability of the changes has yet to be ascertained. It is hoped that through time spent on building strong relationships, strengthening leadership and acknowledging the importance and impact of culture, there is a greater likelihood that the important professional changes begun through this Partnership will be sustained.

Both partners have learned much from one other; ako was a defining characteristic of the Partnership. The SOE has done a great deal of hard work to realise their vision as providers of quality teacher education. SICHE and MEHRD now have an important 
role in supporting and sustaining the ongoing improvement of teacher education in the Solomon Islands. The UOW must also play its part in providing ongoing support, for it is not ethical just to walk away after four and a half years. To this end, the SICHE and the UOW have signed a Memorandum of Understanding that includes such things as staff and student exchanges, collaborative research and ongoing leadership mentoring. The MOU bases its activities on the strong foundation of professional and personal relationships/friendships developed through the partnership.

\section{References}

Alcorn, N. (2010). Knowledge through a collaborative network: A cross-cultural partnership. Educational Action Research, 18(4), 453-466. doi:10.1080/09650792.2010.524783

Coxon, E., \& Munce, K. (2008). The global education agenda and delivery of aid to Pacific education. Comparative Education, 44(2), 147-165. doi:10.1080/03050060802041050

Jansen, J. (2009). Big change question: Can and should school change in the developing world be guided by research from the developed world? Journal of Educational Change, 10(2-3), 239-243.

Kana, T., \& Sore, R. (2005). Community engagement in post-conflict situations: The case of Solomon Islands Report. Honiara: Solomon Islands Government.

Kanbur, R. (2001). Cross-border externalities, international public goods and their implications for aid agencies. New York, NY: Cornell University.

Mancini, J. A., \& Marek, L. I. (2004). Sustaining community-based programs for families: Conceptualization and measurement. Family Relations, 53(4), 339-347.

Mosselson, J., Wheaton, W., \& St. John Frisoli, P. (2009). Education and fragility: A synthesis of the literature. Journal of Education for International Development, 4(1), 1-17.

Mtika, P., \& Gates, P. (2010). Developing learner-centred education among secondary trainee teachers in Malawi: The dilemma of appropriation and application. International Journal of Educational Development, 30(4), 396-404. doi:10.1016/j.ijedudev.2009.12.004

Murphy, J. (2010). Turning around failing organizations: Insights for educational leaders. Journal of Educational Change, 11(2), 157-176.

NZAID. (2006). Terms of reference for a partner relationship between: The School of Education, Solomon Islands College of Higher Education and external teacher training institution for New Zealand. Wellington, New Zealand: Author.

Oplatka, I. (2004). The principalship in developing countries: Context, characteristics and reality. Comparative Education, 40(3), 427-448. doi:10.1080/0305006042000274872

Overton, J., \& Storey, D. (2004). Aid and partnerships: The effectiveness of relationships. Development Bulletin, 65, 41-45.

Ruqebatu, C. (2010). Highly effective principalship in the Solomon Islands. In N. Alcorn (Ed.), Oloketa Tingting Fo Apem Education Long Solomon Islands: Issues in Solomon Islands Education (pp. 103-119). Wellington, New Zealand: NZCER.

Teacher's non-attendance due to lack of housing. (2008, November 24). Solomon Times. Retrieved February 4, 2011, from 
http://www.solomontimes.com/news.aspx?nwID=3072

Strachan, J., Akao, S., Kilavanwa, B., \& Warsal, D. (2010). You have to be a servant to all: Melanesian women's educational leadership experiences. School Leadership and Management, 30(1), 65-76.

Strachan, J., Samuel, J., \& Takaro, M. (2007). Ni Vanuatu women graduates: What happens when they go home? Development in Practice, 17(1), 147-153. doi:10.1080/09614520601092055

Webster, C., Silova, I., Moyer, A., \& McAllister, S. (2011). Leading in the age of postsocialist education transformations: Examining sustainability of teacher education reform in Latvia. Journal of Educational Change, 12(1), 347-370. doi: $10.1007 / \mathrm{s} 10833-010-9152-8$
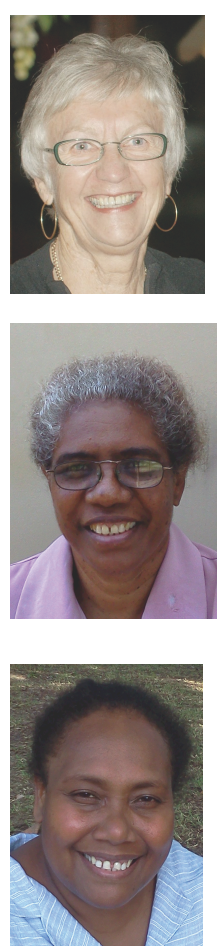

Jane Strachan is an Associate Professor in the Faculty of Education, University of Waikato. Her teaching and research interests are focused on educational leadership, social justice, gender, women, policy development and Pacific education. She is currently supervising masters and doctoral students and teaching in the educational leadership programme. Jane was the Partnership Director for four and a half years.

Susanne Maezama was the Head of the School of Education, in the Solomon Islands for most of the duration of the Partnership. She provided leadership for Partnership activities and reported on progress to stakeholders. She currently teaches in the Education Studies Department and also undertakes contract work within the Curriculum Development Division of the Ministry of Education and Human Resources Development. Her teaching and research interests include secondary education, educational outcomes and leadership.

Janine Simi is currently the Head of the School of Education, at the Solomon Islands College of Higher Education. Prior to taking up the leadership of the School of Education, she worked as a senior lecturer within the Education Studies Department. Her interests include enhancing teaching and learning of special education in the Solomon Islands. She is also interested in researching into educational issues that affect the learning of Solomon Islands children.

\footnotetext{
i At the time of the partnership NZAID was the name of the New Zealand's aid programme. With a change in government there has been a restructuring and NZAID is now know as New Zealand Aid Programme.

ii The dates of the ethnic conflict vary widely in different publications. For the purpose of this article we have used the earliest reference date (1998) as the starting point and the intervention of RAMSI in 2003 as the end date.

iii NZAID has been the major donor to education in the Solomon Islands.

iv The partnership was then extended to four and a half years.

$\checkmark$ SICHE is the main provider of tertiary education in the Solomon Islands. It consists of eight schools: nursing, finance and administration, industrial development, natural resources, marine and fisheries, tourism and hospitality, and education. The School of Education is by far the largest, making up almost half of all enrolments.

vi She chose not to continue in the Head of School role on the completion of her three-year contract.

vii Approach/philosophy.
} 